\title{
El Arbitraje y las Cortes: la experiencia del Azuay*
}

Juan David Vicuña Matovelle $e^{* *}$

Recibido/Received: 29/07/2019

Aceptado/Accepted: 31/07/2019

\begin{abstract}
Sumario: 1. Introducción. 2. Breve referencia a la alternabilidad del arbitraje. 3. Análisis de Casos. 3.1 Acción de protección con medidas cautelares en el marco de un proceso arbitral: Cooperativa de Ahorro y Crédito Jardín Azuayo Ltda. c. SIFISOFT S.A. (Juicio 009-2016). 3.1.1 El proceso arbitral. 3.1.2 La acción de protección con medidas cautelares. 3.2 Acción extraordinaria de protección en el marco de un proceso arbitral: ANDICOAUDI S.A. c. Sergio José Cardona Jiménez (Juicio 005-2016). 3.2.1 El proceso arbitral. 3.2.2 La acción extraordinaria de protección. 3.2.3 El juicio laboral. 3.3 Acción de nulidad de laudo arbitral: Instituto Fiscomisional Técnico Superior Salesiano c. David Gustavo Jiménez Landívar (Juicio 0010-2017). 3.3.1 El proceso arbitral. 3.3.2 La acción de nulidad. 4. Consideraciones finales.
\end{abstract}

Resumen: El presente artículo analiza la alternabilidad del arbitraje a partir de la casuística de la provincia del Azuay. Incluyeel análisis deacciones constitucionales queimpugnaban decisiones de competencia de tribunales arbitrales así como la primera acción de nulidad declarada con lugar en la provincia.

* El autor quiere agradecer a Claudia Albornoz y Francesca Mancino por su ayuda en el análisis de las sentencias para el presente artículo. Un agradecimiento especial a Cinthya Vintimilla del CAM Azuay por la confirmación de ciertos antecedentes fácticos de los casos analizados.

** Abogado del estudio jurídico Cordero\&Asociados Abogados. Abogado por la Universidad del Azuay (presea Honorato Vázquez al mejor egresado de la carrera de Derecho). Ha sido Coentrenador del equipo de arbitraje de la Facultad de Ciencias Jurídicas de la Universidad del Azuay. Correo electrónico:jdvicuna@corderoasociados.com

J. D. Vicuña, "El Arbitraje y las Cortes", Revista Ecuatoriana de Arbitraje, No. 10, 2019, pp. $45-78$. 
Palabras Clave: garantías jurisdiccionales, arbitraje, alternabilidad, cortes.

\section{Arbitration and the Courts : Azuay's experience}

Aвstract: This article studies the alternability of arbitration based on rulings of the Azuay province. It includes an analysis of jurisdictional guarantees that challenged decisions on jurisdiction of the arbitral tribunal and the first annulment of an arbitral award in the province.

KeYWorDs: jurisdictional guarantees, arbitration, alternability, courts.

\section{INTRODUCCIÓN}

No ha sido poco frecuente que partes de un proceso arbitral que no se encuentran conformes con las distintas acciones tomadas, ya sea por el Centro o por el Tribunal Arbitral, intenten acciones de índole judicial y/o constitucional argumentando violaciones a sus derechos, especialmente al debido proceso y a la seguridad jurídica.

Una de las preocupaciones de los practicantes del arbitraje ha sido esta tensión e interacción, en algunos casos obligatoria, entre el arbitraje y las cortes. Surgen dudas como ¿qué concepción tienen los jueces ordinarios del arbitraje?, ¿cómo interpretaría un juez principios especiales del arbitraje?, o ¿hasta qué punto es autónomo el arbitraje?

El objeto del presente artículo es dar respuesta a estas preguntas mediante la casuística, compilando tres experiencias relativamente recientes que constituyen también primeras veces en el marco de procesos arbitrales llevados por el Centro de Arbitraje y Mediación de las Cámaras de la Producción del 
Azuay (en adelante, CAM Azuay), único centro de arbitraje de la provincia ${ }^{1}$.

Así, analizaremos en el presente artículo: (i) una acción de protección interpuesta contra una decisión de competencia de un tribunal arbitral; (ii) una acción extraordinaria de protección interpuesta contra una decisión de competencia de un tribunal arbitral (admitida a trámite por la Corte Constitucional); y (iii) la primera (y hasta la fecha única) sentencia que declara con lugar una acción de nulidad de laudo arbitral en el Azuay.

En todos estos casos, ya sea de forma tangencial y otras veces de forma expresa, se interpreta y analiza instituciones jurídicas que son pilares del arbitraje, como por ejemplo: (i) el estándar bajo el cual se debe verificar el consentimiento de las partes para entender que sometieron sus controversias al arbitraje; (ii) el alcance del principio kompetenz-kompetenz y la posibilidad de revisar en la justicia ordinaria las declaratorias de competencia de los tribunales arbitrales; (iii) el verdadero alcance de la alternabilidad del arbitraje como un método de solución de conflictos independiente de la justicia ordinaria; y (iv) la sujeción de los procesos arbitrales a un control ex post en la justicia ordinaria.

\section{Breve ReFerencia A la Alternabilidad del ARbitraje}

Una de las problemáticas que por antonomasia plantea el arbitraje como método alternativo de solución de conflictos es el verdadero alcance de su alternabilidad, esto es, el grado de interacción que tiene o puede tener la justicia ordinaria ${ }^{2}$ en el marco de un proceso arbitral.

1. Todos los laudos y las decisiones analizadas son de público acceso toda vez que han sido sometidos a la justicia ordinaria.

2. A lo largo del presente artículo, todas las referencias a "justicia ordinaria" deben entenderse que comprenden tanto la justicia ordinaria no constitucional (jueces de lo civil, penal, laboral, etc.) como la justicia constitucional (ya sea jueces ordininarios que conocen garantías jurisdiccionales o la propia Corte Constitucional). 
La Constitución de la República (en adelante, CRE)³ dispone en su artículo 190 que "[s]e reconoce el arbitraje, la mediación y otros procedimientos alternativos para la solución de conflictos. Estos procedimientos se aplicarán con sujeción a la ley, en materias en las que por su naturaleza se pueda transigir [...]" (énfasis añadido). Debemos entender entonces que el arbitraje es alternativo a la justicia ordinaria, característica que se desarrolla a lo largo de otras normas como el artículo 1 de la Ley de Arbitraje y Mediación (en adelante, LAM) ${ }^{4}$ y el artículo 17 del Código Orgánico de la Función Judicial (en adelante, COFJ)5.

Sin embargo, esta alternabilidad no es absoluta pues un proceso arbitral en muchas ocasiones puede y/o debe recurrir o interactuar con los órganos de la justicia ordinaria.

Por un lado, el artículo 7 de la LAM recoge el denominado principio de interdicción de la justicia ordinaria y el principio pro arbitri, que constituyen pilares de la alternabilidad del arbitraje, y proscriben a los jueces ordinarios inmiscuirse en el proceso arbitral, debiendo inhibirse de conocer controversias respecto de las cuales las partes han pactado someterse al procedimiento arbitral ${ }^{6}$.

Este principio está estrechamente ligado a la excepción previa no subsanable constante en el artículo153, numeral 10 del Código Orgánico General de Procesos (en adelante, COGEP), que impide al juez conocer la causa puesta a su conocimiento si verifica la "[e]xistencia de convenio, compromiso arbitral

3. Constitución de la República del Ecuador, RO No. 449, 20/10/2008.

4. Ley de Arbitraje y Mediación, RO No. 417, 14/12/2006.

5. Código Orgánico de la Función Judicial, RO Suplemento No. 544 de 09/03/2009.

6. Ley de Arbitraje y Mediación, N. 4, Art. 7.

Art. 7.- [...] Cuando las partes hayan convenido de mutuo acuerdo someter a arbitraje sus controversias, los jueces deberán inhibirse de conocer cualquier demanda que verse sobre las relaciones jurídicas que las hayan originado, salvo en los casos de excepción previstos en esta Ley. En caso de duda, el órgano judicial respectivo estará a favor de que las controversias sean resueltas mediante arbitraje [...].

7. Código Orgánico General de Procesos, RO No. 506, 22/05/2015. 
o convenio de mediación" ${ }^{\prime}$, debiendo proceder a declarar sin lugar la demanda y ordenar su archivo.

Por otro lado, existen varias ocasiones en las que la LAM expresamente permite $u$ ordena la interacción entre el arbitraje y la justicia ordinaria. Entre ellos tenemos: (i) la renuncia del convenio arbitral9; (ii) el dictado y ejecución de medidas cautelares ${ }^{10}$; (iii) la acción de nulidad de los laudos arbitrales ${ }^{11}$; y (iv) la ejecución (forzosa) de los laudos arbitrales ${ }^{12}$, siguiendo el procedimiento previsto en el COGEP.

En el marco de un proceso arbitral conforme lo previsto en la LAM, de todas las decisiones que puede tomar un tribunal arbitral, existen dos que resultan trascendentales para el proceso, por su incidencia respecto delos derechos eintereses delas partes que se encuentran en litigio: (i) la decisión del tribunal arbitral sobre su competencia para conocer y resolver la controversia, que debe ser tomada en la audiencia de sustanciación ${ }^{13}$; y (ii) el laudo arbitral que pone fin a la controversia.

Respectodeladecisiónquetomeeltribunalsobresucompetencia, la LAMno prevé en forma expresa ningún tipo de recurso que pueda interponer la parte que considere equivocada esta decisión. Esto puede entenderse desde una intención del legislador de defender el principio kompetenz-kompetenz y la capacidad del tribunal para ser, única y exclusivamente, quien resuelva sobre su competencia; tanto es así, que ni siquiera en las causales de nulidad del artículo 31 de la LAM se prevé alguna que haga referencia en forma específica -0 siquiera tangencial-a la declaratoria de competencia de un tribunal arbitral, de modo que, al menos en teoría, estaría proscrito que se realice un control jurisdiccional ex post al respecto.

\footnotetext{
8. Ídem, Art. 153(10).

9. Ley de Arbitraje y Mediación, N. 4, Art. 8.

10. Ídem, Art. 9.

11. Ídem, Art. 31.

12. Ídem, Art. 32.

13. Ídem, Art. 22.
} 
En cuanto a los laudos arbitrales, el artículo 30 de la LAM es claro al señalar que "[1]os laudos arbitrales dictados por los tribunales de arbitraje son inapelables [...]"14 y que "[1]os laudos arbitrales no serán susceptibles de ningún otro recurso que no establezca la presente Ley"15.

Teniendo en cuenta lo manifestado, el objetivo del presente artículo es demostrar en base a la casuística del CAM Azuay, ¿qué ha ocurrido cuando las partes han acudido a la justicia ordinaria para impugnar decisiones de los tribunales arbitrales?

\section{Análisis de casos}

El listado de casos analizados es el siguiente:

\begin{tabular}{|c|c|c|c|c|c|}
\hline No. & $\begin{array}{c}\text { No. } \\
\text { Proceso }\end{array}$ & $\begin{array}{l}\text { Partes } \\
\text { del Proceso } \\
\text { Arbitral }\end{array}$ & $\begin{array}{l}\text { Tipo de } \\
\text { Acción }\end{array}$ & $\begin{array}{c}\text { Decisión } \\
\text { Impugnada }\end{array}$ & Estado de la Causa \\
\hline 1 & $\begin{array}{l}01283- \\
2017- \\
00268\end{array}$ & $\begin{array}{l}\text { Cooperativa } \\
\text { de Ahorro y } \\
\text { Crédito Jardín } \\
\text { Azuayo Ltda. c. } \\
\text { SIFIZSOFT S.A. }\end{array}$ & $\begin{array}{l}\text { Acción de } \\
\text { Protección } \\
\text { con Medidas } \\
\text { Cautelares }\end{array}$ & $\begin{array}{l}\text { Decisión de } \\
\text { Competencia } \\
\text { del Tribunal }\end{array}$ & $\begin{array}{l}\text { Demanda declarada } \\
\text { improcedente en } \\
\text { primera y segunda } \\
\text { instancia }\end{array}$ \\
\hline 2 & $\begin{array}{c}\text { 0638-17- } \\
\text { EP }\end{array}$ & $\begin{array}{l}\text { ANDICOAUDI } \\
\text { S.A. c. Sergio José } \\
\text { Cardona Jiménez }\end{array}$ & $\begin{array}{l}\text { Acción } \\
\text { Extraordinaria } \\
\text { de Protección }\end{array}$ & $\begin{array}{c}\text { Decisión de } \\
\text { Competencia } \\
\text { del Tribunal } \\
\text { Arbitral }\end{array}$ & $\begin{array}{c}\text { Demanda admitida } \\
\text { a trámite por Sala } \\
\text { de Admisión Corte } \\
\text { Constitucional }\end{array}$ \\
\hline 3 & $\begin{array}{l}01100- \\
2018- \\
00002\end{array}$ & $\begin{array}{c}\text { Instituto } \\
\text { Fiscomisional } \\
\text { Técnico Superior } \\
\text { c. David Gustavo } \\
\text { Jiménez Landívar }\end{array}$ & $\begin{array}{c}\text { Acción de } \\
\text { Nulidad de } \\
\text { Laudo Arbitral }\end{array}$ & Laudo & $\begin{array}{c}\text { Demanda declarada } \\
\text { con lugar }\end{array}$ \\
\hline
\end{tabular}

Fuente: Elaboración del autor

14. Ídem, Art. 30.

15. Ibídem. 


\subsection{Acción de protección con medidas cautelares en el marco de un proceso arbitral: Cooperativa de Ahorro y Crédito Jardín Azuayo Ltda. c. SIFIZSOFT S.A. (Juicio 009-2016)}

\subsubsection{El proceso arbitral}

La Cooperativa de Ahorro y Crédito Jardín Azuayo Ltda. (en adelante, la Cooperativa) contrató a SIFIZSOFT S.A., una compañía especializada en software financiero, para la implementación de una plataforma tecnológica que le permita mejorar los servicios que brinda a sus clientes.

Sin embargo, surgieron problemas relativos a los plazos de entrega del software, así como a su funcionamiento, lo que a criterio de la Cooperativa acarreó que no se pueda cumplir con el objeto del contrato, por lo que presentaron una demanda arbitral en la que solicitaron la resolución del contrato junto con una indemnización por los daños y perjuicios causados.

La cláusula de solución de controversias del contrato contenía el siguiente texto:

Cláusula Décimo Sexta: Solución de Controversias.- Si se suscitaren divergencias o controversias en la interpretación o ejecución del presente contrato, cuando las partes no llegaren a un acuerdo amigable directo, podrán utilizar los métodos alternativos para la solución de controversias en el Centro de Mediación de la Cámara de Comercio de Cuenca (énfasis añadido) ${ }^{1617}$.

16. Unidad Judicial Penal de Cuenca, Cooperativa de Ahorro y Crédito Jardín Azuayo Ltda. c. SIFIZSOFT S.A., Proceso No. 01283-2017-00268 (Acción de Protección), 09/02/2017.

17. Pese a que no fue alegado por las partes ni por el tribunal arbitral, es importante señalar que la Disposición Transitoria Primera del Reglamento Interno del CAM Azuay dispone: "Todas las cláusulas compromisorias relativas a los medios alternativos de solución de conflictos que se hayan pactado en relación a los Centros de las Cámaras de Comercio, Industrias y Construcción de Cuenca, se entenderán sometidas a conocimiento del Centro de Arbitraje y Mediación de las Cámaras de la Producción del Azuay y del presente Reglamento”. 
La parte actora puntualizó en su demanda que, a efectos de evitar o subsanar cualquier patología que el tribunal arbitral pudiera detectar en la cláusula (i) es evidente que las partes se referían al CAM Azuay y (ii) los métodos alternativos para la solución de controversias que se llevan a cabo en el centro son tanto el arbitraje como la mediación, por lo que, inclusive en caso de duda, debería aplicarse el principio pro arbitri contenido en el artículo 7 de la LAM, en concordancia con el artículo 76 de la CRE y el artículo 6 del COFJ.

Se acompañó a la demanda un acta de imposibilidad de acuerdo del mismo Centro, con la cual la parte actora pretendió demostrar que se agotó la etapa previa de mediación, así como que no debería llamarse a una nueva audiencia de mediación intraprocesal conforme lo dispuesto en el artículo 15 de la LAM.

SIFIZSOFT S.A. contestó la demanda rechazando todos los argumentos referentes a los méritos de la demanda, y en cuanto a la competencia del Centro (y del tribunal arbitral que se conforme) para conocer y resolver la controversia, presentó una excepción de Incompetencia del Juez.

Este argumento se centró en que se trataba de una cláusula arbitral patológica o insuficiente, afirmando que su contenido resultaba "incoherente, ambiguo e inaplicable" por lo que "no cumple con requisitos esenciales para que pueda ser considerada una cláusula arbitral en sentido propio ni para que surta efectos legales y sea aplicable, por lo que tiene vicios insubsanables [...]"18.

Los "vicios insubsanables" alegados por la demandada fueron ${ }^{19}$ :

(i) No existe una obligación expresa de las partes de someterse ni a la mediación ni al arbitraje como método de solución de

18. Contestación a la demanda por parte de SIFIZSOFT S.A. en el marco del proceso arbitral que derivó la acción de protección No. 01283-2017-00268.

19. Unidad Judicial Penal de Cuenca, N. 16. 
controversias, pues la palabra "podrán" hace referencia a una atribución facultativa, por lo que, si no hay acuerdo mutuo entre las partes, no existe obligación de someterse a estos métodos alternativos de solución de conflictos.

(ii) En la cláusula no se hace referencia de manera expresa al arbitraje en ningún punto. Se trata de una cláusula general que se refiere a "métodos alternativos" y si se analiza la cláusula en su integralidad, el arbitraje queda excluido del convenio ya que se refieren a un "Centro de Mediación".

(iii) Se hace referencia en la cláusula al "Centro de Mediación de la Cámara de Comercio de Cuenca", sin embargo, esta Cámara no tiene ningún centro de mediación legalmente autorizado.

Indican que se trata de un caso que la doctrina ha denominado una "cláusula arbitral diminuta" por su carácter general, vago y difuso; que además es una "cláusula confusa" por cuanto las partes no se someten expresamente al arbitraje ni tampoco ante una institución claramente definida. Esto se evidencia en el hecho que (i) se ha identificado a una institución inexistente; (ii) no existe determinación inequívoca de sometimiento al arbitraje; (iii) el convenio es ambiguo y (iv) se trata de un "convenio en blanco" ya que omite la forma de designación de los árbitros, así como la modalidad del arbitraje (en derecho o en equidad).

En base a los argumentos indicados, SIFIZSOFT S.A. sostuvo que esta cláusula contractual no cumplía con los requisitos de un convenio arbitral previstos en el artículo 5 de la LAM, por lo que el tribunal que fuere designado debía declararse incompetente y abstenerse de conocer y resolver la causa.

Posteriormente se posesionó un tribunal arbitral ${ }^{20}$ integrado por tres árbitros, y mediante decisión tomada con

20. Es de notar el hecho que el tribunal arbitral, al tratarse de un arbitraje en equidad por no haber las partes dispuesto lo contrario conforme lo proscribe el artículo 3 de la LAM, estuvo integrado por dos abogados y un ingeniero civil. 
fecha 09 de enero de 2017 en la audiencia de sustanciación, se declaró competente para conocer y resolver la controversia.

El argumento del tribunal para declararse competente ${ }^{21}$ fue únicamente que la existencia misma de la cláusula de solución de controversias demuestra la voluntad y el consentimiento común de las partes de someterse a los medios alternativos de solución de conflictos, por lo que correspondía aplicar (i) el principio pro arbitri; y (ii) el artículo 1576 del Código Civil referente a la interpretación de los contratos, que dispone que “[c]onocida claramente la intención de los contratantes, debe estarse a ella más que a lo literal de las palabras" ${ }^{22}$.

\subsubsection{La acción de protección con medidas cautelares}

El 02 de febrero de 2017 SIFIZSOFT S.A. interpuso una acción de protección con medidas cautelares que recayó por sorteo en la Unidad Judicial Penal de Cuenca y fue signada con el número de juicio 01283-2017-00268.

La parte demandada en este proceso fueron los tres árbitros que conformaban el tribunal arbitral. El acto violatorio de derechos fundamentales impugnado fue "la decisión del Tribunal de Arbitraje y Mediación del [CAM Azuay] expresada en audiencia de sustanciación [...] mediante la cual se declara competente para conocer y resolver la demanda $[\ldots]^{\prime 23}$.

El argumento de SIFIZSOFT S.A. fue que, al declararse competente el tribunal arbitral, la compañía quedó en absoluta indefensión, toda vez que contra la decisión de competencia de un tribunal arbitral no cabe recurso alguno. Se señalaron como derechos fundamentales presuntamente violados: (i) la

21. Unidad Judicial Penal de Cuenca, N. 16.

22. Código Civil, RO Suplemento No. 45, 24/06/2005. Unidad Judicial Penal de Cuenca, N. 16.

23. Unidad Judicial Penal de Cuenca, N. 16. 
seguridad jurídica ${ }^{24}$; (ii) el derecho a ser juzgado por su juez natural ${ }^{25}$; $y$, (iii) derecho a la defensa ${ }^{26}$.

También se pretendió justificar la idoneidad de la acción de protección alegando la inexistencia de otro mecanismo de defensa judicial adecuado y eficaz, toda vez que ni la LAM ni ninguna otra norma del ordenamiento jurídico ecuatoriano prevé la posibilidad de impugnar la decisión de los árbitros sobre su competencia, como sí sucede en otros países, citando el caso de España que prevé la revisión de la decisión mediante una acción de anulación del laudo ${ }^{27}$.

La pretensión concreta fue que (i) se declare la vulneración de derechos fundamentales de SIFIZSOFT S.A.; (ii) se deje sin efecto la declaratoria de competencia del tribunal arbitral; $\mathrm{y}$, (iii) se declare la nulidad del proceso arbitral ${ }^{28}$.

Adicionalmente, se solicitó como medida cautelar (que fue concedida), que con fundamento en el artículo 87 de la CRE y artículos 13, numeral 5, 26 y 27 de la Ley Orgánica de Garantías Jurisdicciones y Control Constitucional (en adelante, LOGJCC), se disponga "la suspensión del proceso arbitral [...] hasta que se resuelva esta causa".

Se fundamentó la medida la amenaza de violación de derechos constitucionales que podrían producir un daño grave, toda vez que el arbitraje se encontraba en etapa de prueba, y la práctica de estos medios probatorios generarían importantes perjuicios económicos a la compañía, que adicionalmente, se encontraba domiciliada en la ciudad de Quito lo cual incrementaría estos costos.

24. Constitución de la República del Ecuador, N. 3, Art. 82.

25. Ídem, Art. 76(7)(k).

26. Ídem, Art. 76(7).

27. Ley 60/2003 de Arbitraje de España, Art. 22(3).

28. Unidad Judicial Penal de Cuenca, N. 16. 
El tribunal arbitral, al contestar la demanda en la audiencia convocada para el efecto, alegó que: (i) "la acción planteada es insólita"; (ii) que "la decisión de un tribunal en la que se declara competente no tiene ningún tipo de recurso"; y, (iii) que "[en el proceso arbitral] sólo cabe la nulidad del laudo arbitral cuando todo el proceso arbitral haya concluido y [deesta decisión, eventualmente] una acción extraordinaria de protección". Además, calificaron a la acción como (iv) "un ataque directo [al arbitraje como] método alternativo de solución de conflictos amparado en la [CRE]"29.

En primera instancia, se declaró sin lugar la acción de protección planteada. La jueza determinó que para analizar la procedencia o no de la acción debía resolver las siguientes interrogantes ${ }^{30}$ :

¿Procede la acción de protección contra una decisión de un Tribunal Arbitral?

La respuesta fue que "eminentemente no", por cuanto el artículo 88 de la CRE señala que la acción de protección procede contra actos $\mathrm{u}$ omisiones de cualquier autoridad pública no judicial, y en el caso concreto, se impugna un acto emanado de un tribunal arbitral en conocimiento de un caso, y que conforme lo prescrito en el artículo 1 de la LAM “[el] actuar [de los árbitros] se asimila a la administración de justicia" ${ }^{31}$, por lo que en base al artículo $17 \mathrm{COFJ}$, resulta improcedente la acción al enmarcarse en las causales de improcedencia del artículo 42 de la LOGJCC.

Adicionalmente, indicó que el laudo que se llegue a dictar es susceptible de la acción de nulidad prevista en el artículo 31 de la LAM, lo que torna de igual forma improcedente la acción de protección.

\footnotetext{
29. Ibídem.

30. Ibídem.

31. Ley de Arbitraje y Mediación, N. 4, Art. 1.
} 
¿Existirá afectación de derechos constitucionales de SIFIZSOFT S.A. con la decisión del Tribunal Arbitral, al resolver declararse competente para conocer la controversia?

La respuesta fue igualmente negativa, puesto que no se ha probado que exista una vulneración a ningún derecho constitucional. De manera concluyente, la sentencia manifiesta:

Es evidentemente imposible e incuestionable que por medio de una acción de protección constitucional, se intente analizar la legalidad o legitimidad de una resolución emitida por el Tribunal de Arbitraje del Centro de Arbitraje y Mediación de las Cámaras de la Producción del Azuay ${ }^{32}$.

Finalmente, la jueza consideró que existió un abuso del derecho por parte de SIFIZSOFT S.A. al plantear una acción de protección contra una resolución de un tribunal arbitral "con la finalidad de retardar el proceso por intereses económicos" y calificó la acción de temeraria.

SIFIZSOFTS.A. apeló esta sentencia, y en segunda instancia el caso fue conocido y resuelto por la Sala de lo Laboral de la Corte Provincial de Justicia del Azuay, que ratificó la sentencia de primera instancia concordando en todo lo expuesto por la jueza a quo, salvo la declaratoria de temeridad, al considerar que es una figura propia de materia penal y que no cabe por tanto en una acción de naturaleza constitucional ${ }^{33}$.

32. Unidad Judicial Penal de Cuenca, N. 16.

33. Sala de lo Laboral de la Corte Provincial del Azuay, SIFISOFT S.A. c. Centro de Arbitraje y Mediación de las Cámaras de la Producción del Azuay, Causa No. 01283-2017-00268, 20/04/2017. 


\subsection{Acción extraordinaria de protección en el marco de un proceso arbitral: ANDICOAUDI S.A. c. Sergio José Cardona Jiménez (Juicio 005-2016)}

\subsubsection{El proceso arbitral}

La compañía ANDICOAUDI S.A. suscribió un contrato civil de prestación de servicios profesionales con el señor Sergio José Cardona Jiménez con el objeto de que, cuando la compañía lo requiera, este último prestaría "sus servicios en calidad de piloto de avión en el lugar y tiempo que la compañía lo requiera; para viajes dentro del territorio nacional como al extranjero".

Como contraprestación por los servicios que prestaría el profesional, la compañía contratante debería cancelar mensualmente al piloto un valor fijo. Asimismo, se estipuló una cláusula denominada "Relación Civil entre las Partes" que determinaba que el contrato era de índole civil, sin que existiera ninguna relación laboral de ninguna clase entre las partes.

Este contrato contenía una cláusula arbitral que, en su parte pertinente determinaba:

Décimo Primera: Controversias.- Toda controversia o diferencia relativa a este contrato, a su ejecución, liquidación e interpretación, será sometida obligatoriamente en primera instancia a mediación en el Centro de Arbitraje y Mediación (CAM) de las Cámaras de la Producción del Azuay con sede en la ciudad de Cuenca. En el evento que el conflicto no fuere resuelto mediante ese procedimiento las partes la someterán a la resolución de un tribunal de Arbitraje de las Cámaras de la Producción del Azuay, que se sujetará a lo dispuesto en la Ley de Arbitraje y Mediación, el reglamento del CAM, y a las siguientes normativas y preceptos:

El Tribunal estará integrado por un árbitro, designado por el CAM de las Cámaras de la Producción del Azuay 
de conformidad a lo establecido en la Ley de Arbitraje y Mediación. El Tribunal decidirá en derecho (énfasis añadido) ${ }^{34}$.

ANDICOAUDI S.A. presentó una demanda arbitral el 25 de mayo de 2016 en la cual alegó que el piloto contratado repentinamente dejó de cumplir sus obligaciones contractuales y "nunca más apareció a prestar sus servicios" fallando en asistir a un vuelo previamente agendado por la compañía, para el cual ya se habían comprado otros pasajes aéreos, tickets de hotel, entre otros. Asimismo, el piloto se había comprometido a realizar un curso de entrenamiento en Estados Unidos que ya había sido pagado por la compañía, y tras su ausencia no lo completó.

La compañía demandó en virtud de lo que ellos consideraban era un flagrante incumplimiento de las obligaciones contractuales del piloto, solicitando que el tribunal arbitral declare: (i) el incumplimiento del contrato por parte del piloto; (ii) declare la terminación del contrato; y (iii) se condene al piloto al pago de daños y perjuicios por múltiples conceptos, entre los que se incluyeron, los gastos del viaje no realizado, los pagos al curso de entrenamiento, entre otros.

El piloto contestó la demanda negando todas las pretensiones referentes al fondo de la controversia, y en lo referente a la competencia del tribunal, alegó que existía incompetencia en razón de la materia. El fundamento fue que el contrato "si bien contiene cláusulas que en lo formal quieren aparentar un contrato de prestación de servicios profesionales autónomo e independiente ${ }^{\prime 35}$ se trata en realidad de una relación laboral, por lo que se interpuso una excepción de incompetencia de la autoridad arbitral para conocer una controversia "cuya competencia es exclusiva y excluyente de

34. Extracto del contrato de la controversia entre ANDICOAUDI S.A. c. Sergio José Cardona Jiménez.

35. Contestación a la demanda por parte de Sergio José Cardona Jiménez en el marco del proceso arbitral entre entre ANDICOAUDI S.A. c. Sergio José Cardona Jiménez, que derivó la acción extraordinaria de protección No. 0638-17-EP. 
los jueces del trabajo". Esta excepción se fundamentó en el artículo 129 del COFJ y el artículo 568 del Código del Trabajo ${ }^{36}$.

Para el efecto, se adjuntaron como prueba varios correos electrónicos y comunicaciones entre las partes, con los que se justificó que al piloto se le exigía cumplir un horario y, cuando no esté realizando labores de vuelo, encontrarse en la sede de la compañía.

Una vez constituido el tribunal arbitral, se realizó la audiencia de sustanciación conforme lo previsto en el artículo 22 de la LAM, en la cual el tribunal se declaró no competente para conocer esta controversia. Una particularidad de esta decisión es el criterio del árbitro único respecto de la aplicabilidad del COGEP en el marco del proceso arbitral. La decisión de competencia realiza varias reflexiones y aseveraciones respecto de la supletoriedad y/o obligatoriedad de aplicar el COGEP, señalando en su parte pertinente lo siguiente:

PRIMERO.- Conforme consta de las constancias procesales, la demanda arbitral fue presentada en fecha 25 de mayo del 2016, lo que implica que para esa fecha el Código General de Procesos (COGEP) se encontraba en plena vigencia en el ordenamiento jurídico ecuatoriano [...]

SEGUNDO.- El mentado Código establece nuevos procedimientos que deben usarse obligatoriamente para la sustanciación de los procesos judiciales, con el objetivo de concretar el principio de celeridad procesal, que abarca el principio general de economía procesal [...] en el cual se ordena que las excepciones planteadas por la parte demandada o reconvenida deben ser fundamentadas, existiendo además la posibilidad de plantear las llamadas "excepciones previas", las mismas que se encuentran expresamente señaladas en el COGEP en su artículo 153 y entre las cuales se encuentra la "1. Incompetencia de la o del juzgador", ante las cuales precisamente el administrador de justicia debe pronunciarse para sanear el proceso y evitar de esta forma que las partes procesales incurran en gastos innecesarios de tiempo y

36. Código del Trabajo, RO Suplemento No. 167, 16/12/2005. 
recursos, circunstancia que a criterio de este Árbitro Único resulta ser una de las ventajas más apreciables del nuevo código adjetivo procesal.

TERCERO.- El COGEP es plena y obligatoriamente aplicable a los casos de Arbitraje, según lo dispone el artículo 37 de la Ley de Arbitraje y Mediación y a la Disposición Reformatoria Primera del COGEP, circunstancia que aparte de ser legalmente aplicable es conocida perfectamente por las partes procesales [...] (énfasis añadido $)^{37}$.

Respecto de la excepción de incompetencia, se determinó que todo ciudadano tiene derecho a ser juzgado por su juez natural ${ }^{38}$ y que, la sola existencia de la cláusula arbitral no vuelve per se arbitrable a una controversia; sino que debe ser analizada de manera previa por el tribunal que la conozca, si la materia puesta a consideración para la resolución es o no transigible ${ }^{39}$.

El árbitro único determinó que, de las pruebas aportadas por las partes, se desprendía sin duda alguna que la relación entre ellas era de índole laboral, por lo que no constituía materia transigible, señalando:

NOVENA.- Con las pruebas antes descritas, es el criterio del suscrito que, a pesar de la denominación y la forma que se ha dado al contrato que dio inicio a la relación entre las partes como uno de prestación de servicios profesionales, en la especie se ha probado la pertinencia de la excepción de incompetencia formulada por el demandado, en tal virtud las obligaciones derivadas del contrato deben ser reclamadas en la forma pertinente a la materia y conocidas por el Juez competente que en este caso no es el presente Tribunal.

Por lo dicho, este Tribunal Arbitral, acepta la excepción de falta de competencia alegada por el demandado y dispone el archivo de la presente causa dejando a salvo los derechos de los que las partes se crean asistidos para hacerlos valer ante los órganos correspondientes $[\ldots]^{40}$.

37. Decisión del árbitro único en el marco del proceso arbitral entre ANDICOAUDI S.A. c. Sergio José Cardona Jiménez.

38. Constitución de la República del Ecuador, N. 3, Art. 76(3).

39. Ídem, Art. 190.

40. Decisión del árbitro único, N.37. 
ANDICOAUDI S.A. presentó un escrito en el que solicitaba que se declare la nulidad del auto dictado en la audiencia de sustanciación y además pedía una aclaración de ciertos puntos, manifestando que, (i) por la sola existencia del convenio arbitral debía declararse competente el árbitro con fundamento en el artículo 22 de la LAM, toda vez que el principio kompetenz-kompetenz faculta al tribunal a decidir sobre su competencia única y exclusivamente en virtud del texto convenio arbitral y no de las pruebas aportadas por las partes (que solamente pueden ser valoradas tras una declaratoria de competencia), con lo cual se produjo una vulneración al debido proceso; y (ii) que el COGEP no es aplicable en lo absoluto por diferenciarse los procesos judiciales de los arbitrales, por lo que mal pueden existir referencias a excepciones previas como a la audiencia preliminar. Se alegó que la decisión tomada vulnera directamente los derechos constitucionales de la compañía a la defensa y al debido proceso.

Elárbitroúnico respondió a este pedido mediante providencia dictada con fecha 02 de febrero de 2017 mediante la cual señalaba (i) que las causas de nulidad procesal se encuentran expresamente detalladas en la ley, lo cual no se cumple en el caso; y (ii) que el COGEP es plenamente aplicable al proceso arbitral en virtud del artículo 37 de la LAM determinando que "la aplicación del COGEP será obligatoria en todo aquello que no se encuentra previsto en la Ley de Arbitraje y Mediación, así la contestación como el tratamiento de las excepciones planteadas deben sujetarse a este cuerpo normativo" ${ }^{41}$ (énfasis añadido).

Tras algunos escritos posteriores presentados por las partes, el árbitro único se ratificó en su decisión, y ANDICOAUDI S.A. presentó una acción extraordinaria de protección.

41. Respuesta del árbitro único a la solicitud de ANDICOAUDI S.A. para la nulidad del proceso arbitral. 


\subsubsection{La acción extraordinaria de protección}

Esta garantía jurisdiccional se interpuso "en contra del auto [de declaratoria de incompetencia del tribunal arbitral] [...] así como del auto de nulidad y aclaración [...] en que se niega lo solicitado $[\ldots]^{\prime \prime 4}$.

Se pretendió justificar el requisito de haber agotado los recursos ordinarios y extraordinarios ${ }^{43}$ alegando que conforme el artículo 30 de la LAM -referente a la inapelabilidad de los laudos arbitrales- "la etapa del juicio arbitral se encuentra agotada, toda vez que no cabe recurso de apelación de la decisión [de competencia del tribunal arbitral]"44 y que tampoco cabe "una petición de nulidad de laudo arbitral, por no haberse dictado el mismo en razón de lo ya relatado" ${ }^{45}$.

Se identificaron como derechos constitucionales vulnerados en la decisión: (i) el derecho al debido proceso en la garantía del cumplimiento de las normas y derechos de las partes ${ }^{46}$; (ii) el derecho a la defensa en la garantía de la motivación ${ }^{47}$; y (iii) la seguridad jurídica ${ }^{48}$.

Como pretensión concreta de su demanda, ANDICOAUDI S.A. solicitó que se declare la vulneración de sus derechos constitucionales, y que en consecuencia (i) se acepte la acción extraordinaria de protección; (ii) se deje sin efecto la decisión de competencia tomada por el tribunal arbitral; y (iii) se disponga que otro árbitro del Centro conozca y resuelva la demanda planteada.

El Centro remitió el expediente a la Corte Constitucional y el proceso fue signado con el número 0638-17-EP. La Sala

42. Corte Constitucional del Ecuador, Proceso No. 0638-17-EP.

43. Ley Orgánica de Garantías Jurisdiccionales y Control Constitucional, Art. 61(3), RO Sup No. $52,22 / 10 / 2009$.

44. Corte Constitucional del Ecuador, N. 42.

45. Ibídem.

46. Constitución de la República del Ecuador, N. 3, Art. 76(1).

47. Ibídem.

48. Ídem, Art. 82. 
de Admisión admitió a trámite la demanda con fecha 06 de junio de 2017, resolviendo sin realizar un mayor análisis de los argumentos de ninguna de las partes:

CUARTA.- La Ley Orgánica de Garantías Jurisdiccionales y Control Constitucional, en sus artículos 61 y 62, establece los requisitos de admisibilidad para la acción extraordinaria de protección. De la revisión de la demanda propuesta, y de los documentos que se acompañan a la misma, se encuentra que, en el presente caso, se cumplen los requisitos de admisibilidad previstos en los artículos referidos [...] por lo que esta Sala, ADMITE a trámite la acción extraordinaria de protección No. 0638-17-EP, sin que ello constituya un pronunciamiento sobre la materialidad de la pretensión ${ }^{49}$.

A la fecha de elaboración del presente artículo, no se ha dictado aún una sentencia defondo que resuelva la controversia. Sin embargo, es importante a efectos de la decisión que vaya a tomarse, tomar en consideración los hechos subsecuentes que detallamos a continuación.

\subsubsection{El juicio laboral}

El 13 de marzo de 2019, el piloto presentó una demanda por pago de haberes laborales que por sorteó radicó en la Unidad Judicial del Trabajo de Cuenca y fue signada con el número 01371-2019-00118. El piloto alegó en su demanda que el contrato de servicios profesionales que suscribió con ANDICOAUDI S.A. en realidad configuró la existencia de una relación laboral y demandó el pago de remuneraciones no canceladas, horas suplementarias y horas extraordinarias con los recargos respectivos, vacaciones, despido intempestivo, el desahucio, fondos de reserva y costas procesales $^{50}$.

49. Corte Constitucional del Ecuador, N. 42.

50. Unidad Judicial del Trabajo de Cuenca, Sergio José Cardona Jiménez c. ANDICOAUDI S.A., Proceso No. 01371-2019-00118. 
Dentro de las pruebas presentadas por el piloto inclusive se adjuntó el expediente del proceso arbitral, pretendiendo demostrar (i) que ya existió un pronunciamiento por parte del árbitro único determinando que se trata de una controversia netamente laboral; y que, (ii) al haber sido puesta esta controversia en conocimiento de un tribunal arbitral, no podría alegarse de modo alguno que se estaba violando la cláusula de resolución de controversias prevista en el contrato.

ANDICOAUDI S.A. contestó la demanda negando las pretensiones de fondo y planteó como excepciones previas -que fueron desechadas por la jueza en la primera fase de la audiencia única prevista en el COGEP-: (i) existencia de compromiso arbitral ${ }^{51}$; (ii) incompetencia de la autoridad ${ }^{52} ; \mathrm{y}$ (iii) inadecuación del procedimiento ${ }^{53}$.

Con fecha 28 de junio de 2019, se dictó la sentencia de primera instancia en este juicio, que declara con lugar la demanda planteada por el piloto, resolviendo en su parte pertinente $^{54}$ :

(i) Sobre las excepciones previas planteadas: Todas tenían como fundamento la existencia del convenio arbitral, sin embargo, la jueza determinó que, pese a que a ella no le es vinculante el pronunciamiento que pueda haber hecho sobre su competencia el tribunal arbitral, a todo evento, ya se había cumplido el requisito de acudir al arbitraje señalando:

En la Audiencia Única y en el momento de fundamentar cada excepción es que se denota que aquello a lo que hacía referencia en esta excepción es a un "convenio arbitral" de obligatorio cumplimiento para las partes, y se alega que por ello estoy en la obligación de inhibirme de conocer esta demanda y dejar que sea el tribunal arbitral el que conozca y resuelva

51. Código Orgánico General de Procesos, N. 7, Art. 153(10).

52. Ídem, Art. 153(1).

53. Ídem, Art. 153(4).

54. Unidad Judicial del Trabajo de Cuenca, N. 50. 
esta controversia surgida entre ANDICOAUDI S.A. y el señor Sergio Cardona Jiménez, más debo recordar que este proceso ya fue sometido ante el árbitro único [...] quien dictó un Auto Inhibitorio por considerar que no tenía competencia dentro del caso puesto a su conocimiento, por tanto ya se cumplió incluso con aquello que consta en el contrato que fue presentado en aquel proceso y hoy en este que nos ocupa.

No quiero con ello decir que aquella excepción que fue acogida por el señor árbitro sea para mí vinculante ni mucho menos, simplemente muestro que ya se sometió a las instancias que dice el demandado debieron ser sometidas, si el auto inhibitorio no le parece el correcto ello no quiere decir que no se cumplió aquello que hoy alega debe ser acatado ${ }^{55}$.

(ii) Sobre la acción extraordinaria de protección: Se indicó que por mandato legal, esta no suspende los efectos del auto impugnado.

(iii) Sobre la naturaleza jurídica del contrato de prestación de servicios profesionales: se determinó que se lograron probar todos los elementos de la relación laboral, y en consecuencia, se dispuso el pago de varios de los rubros reclamados por el piloto.

De la sentencia de primera instancia, ambas partes presentaron recursos de apelación: (i) el piloto solicitando que se ordene el pago de los valores que fueron declarados sin lugar; y, (ii) la compañía apeló alegando que no existe relación laboral y, subsidiariamente -en caso de que existiera-, los valores a pagar son menores.

A la fecha de elaboración del presente artículo, ambos recursos de apelación fueron concedidos para ante la Sala de lo Laboral de la Corte Provincial de Justicia del Azuay, sin que se haya dictado una sentencia de fondo, teniendo fijada como fecha de audiencia el 11 de septiembre de 2019.

55. Ibídem. 
Sin embargo, resulta trascendental a efectos de lo que pueda resolver la Corte Constitucional, considerar que ya ha existido un pronunciamiento de la justicia ordinaria que determina que la naturaleza jurídica del contrato que contiene el convenio arbitral es laboral e inclusive se ha dispuesto el pago de valores. Con ello, en el supuesto de que se acepte la acción extraordinaria de protección, y el proceso regrese al Centro, el nuevo árbitro único que conozca la controversia se vería obligado a por lo menos tener en cuenta, previo a tomar una decisión de competencia o para dictar el laudo en caso de declararse competente, la decisión definitiva que tenga el juicio laboral, cuya existencia ya ha sido puesta en conocimiento de la Corte Constitucional.

\subsection{Acción de nulidad de laudo arbitral: Instituto Fiscomisional Técnico Superior Salesiano c. David Gustavo Jiménez Landívar (Juicio 0010-2017)}

\subsubsection{El proceso arbitral}

El Instituto Fiscomisional Técnico Superior Salesiano (en adelante, el Instituto) contrató los servicios del arquitecto David Gustavo Jiménez Landívar (en adelante, el arquitecto) para el contrato con modalidad llave en mano para ejecutar la construcción de la obra civil integral de edificación deportiva con la piscina semiolímpica en el Instituto Fiscomisional Técnico Superior Salesiano.

El Instituto consideró que existieron incumplimientos contractuales por parte del arquitecto por lo que demandó la terminación del contrato y la indemnización por daños consistentes en: (i) la devolución de los valores cancelados y aún no devengados por el arquitecto; (ii) la ejecución de la garantía de fiel cumplimiento; (iii) el pago de costas procesales que comprendería 
la tasa del centro y los honorarios de los abogados defensores; así como (iv) la reparación del daño a la imagen pública de la institución en un diario de amplia circulación de la ciudad.

Elarquitecto contestóla demanda conuna negativa expresa, alegando que cumplió todas sus obligaciones a cabalidad, y que ha sido más bien el Instituto el que ha incumplido sus obligaciones, concretamente el pago de varias planillas y de dos cuotas correspondientes a los meses de febrero y abril de 2017, conforme la cláusula sexta del contrato, pues se había pactado que el pago de la obra se haría en parte mediante desembolsos pactados en fechas determinadas.

El arquitecto interpuso junto a su contestación una reconvención, mediante la cual el reclamó: (i) la terminación del contrato; y (ii) el pago de los daños y perjuicios causados. Entre los rubros que componían los daños reclamados se encontraba el pago de las cuotas correspondientes a los meses de febrero y abril de 2017. Cabe destacar que el arquitecto no solicitó dentro de su pretensión el pago de intereses respecto de estos valores pendientes.

Ninguna de las partes objetó la competencia del tribunal arbitral para conocer y resolver la controversia y el caso fue resuelto por un árbitro único. El laudo fue dictado con fecha 07 de septiembre de 2018 y el tribunal resolvió declarar sin lugar la demanda, aceptando parcialmente la reconvención. En el laudo se dispuso, en su parte pertinente, la terminación del contrato y ordenó al Instituto:

2.- Que los señores [representantes legales del Instituto] cancelen en forma inmediata al [arquitecto] la cantidad que corresponde a la suma de los pagos que contractualmente debieron efectuar los meses de febrero y abril del 2017, con más los intereses correspondientes, los mismos que se calcularán a la tasa máxima legal vigente a la fecha en la que se realice el pago y a partir de la fecha de la presentación de la reconvención (énfasis añadido). 
El Instituto interpuso una acción de nulidad en contra de este laudo, que fue conocida y resuelta por el Presidente de la Corte Provincial de Justicia del Azuay.

\subsubsection{La acción de nulidad}

El Instituto invocó en su demanda el literal d) del artículo 31 de la LAM que tipifica como causal de nulidad que "[e] 1 laudo se refiera a cuestiones no sometidas al arbitraje o conceda más allá de lo reclamado" ${ }^{\prime 2}$.

Se fundamentó la demanda en las dos hipótesis fácticas de esta causal, alegando: (i) que el laudo se refirió a cuestiones no sometidas al arbitraje, pues en la parte expositiva del laudo no se hace referencia alguna al libelo de la reconvención pero "paradójicamente, la parte resolutiva de la decisión arbitral, constituye aceptar parcialmente la pretensión de la contrademanda"; (ii) que el laudo concedió más allá de lo reclamado, principalmente por cuanto el reconveniente únicamente solicitó el pago de un valor determinado; y, (iii) que el árbitro de forma arbitraria se extralimitó disponiendo el pago de intereses calculados a la máxima tasa legal ${ }^{57}$.

El arquitecto contestó la acción de nulidad manifestando, en su parte pertinente: (i) que la cuantía total de su reconvención es superior al monto que fue ordenado cancelar por parte del Instituto, por lo que mal podría hablarse de un laudo que concede más allá de lo reclamado; además (ii) el artículo 1575 del Código Civil impone el pago de intereses por mora y el árbitro debió aplicarlo en virtud del principio iura novit curia; y (iii) el COGEP prevé en su artículo 112 las causales de nulidad de una sentencia y, por tratarse de una norma más moderna y

56. Ley de Arbitraje y Mediación, N. 4, Art. 31.

57. Corte Provincial de Justicia del Azuay, Presidencia, Instituto Fiscomisional Técnico Superior Salesiano c. David Gustavo Jiménez Landivar, Proceso No. 01100-2018-00002. 
de rango orgánico estas causales prevalecen por sobre las del artículo 31 de la LAM, por lo que al no estar enmarcada la acción de nulidad de laudo en ninguna de estas, debía ser desechada pues "no pueden tolerarse en la unidad y coherencia del sistema jurídico dos regímenes distintos para la acción de nulidad, uno para la justicia ordinaria o común y otro para los laudos arbitrales cuyo valor es de sentencia".

Con fecha 06 de noviembre de 2018, el Presidente de la Corte Provincial de Justicia dictó la primera sentencia en la historia del Azuay mediante la cual se declara con lugar una acción de nulidad de un laudo arbitral. Dentro de las partes relevantes de la motivación de la sentencia encontramos:

\section{Respecto de los límites del juez que conoce una acción de nulidad}

Este Juez Presidente, está facultado para examinar si procede la causal de nulidad alegada por los actores, pero no tiene competencia para analizar el asunto de fondo, porque el laudo es un título de ejecución -Art. 362.2 COGEP- que no admite ninguna clase de recurso que no sea los horizontales de aclaración y ampliación.

Con esta argumentación, el Presidente inició delimitando el ámbito de su competencia, determinando -no en base al artículo 31 de la LAM, sino en base al COGEP- que no sería posible analizar el fondo del laudo. Se citó también el pronunciamiento que tuvo la ex Corte Suprema de Justicia en el caso Latin American Telecom Inc. c. Pacifictel que señala:

[...] el objetivo de la acción de nulidad no es otro que el verificar la existencia o no de determinados vicios anulatorios en el procedimiento arbitral [...] lo cual impide a los órganos jurisdiccionales que conocen tal acción, el dictaminar sobre el fondo del asunto sometido al procedimiento arbitral ya que lo que en éste se resuelve, de conformidad con el artículo 32 de la Ley de Arbitraje y Mediación, tiene efecto de sentencia 
ejecutoriada y de cosa juzgada [...]. No corresponde a esta Sala, atenta la naturaleza de la acción de nulidad de laudo [...], analizar si el Tribunal arbitral hizo bien o mal en acoger los principios y las bases legales que fundamentaron su decisión, porque dicha acción de nulidad de laudo no comporta un recurso de alzada contra la resolución arbitral adoptada ${ }^{58}$.

Respecto de las causales por las que se puede declarar nulo un laudo y su relación con las causales de nulidad de sentencia previstas en el COGEP

El Presidente desechó la argumentación relativa a la prevalencia de las causales de nulidad de sentencia ${ }^{59}$ señalando:

Los motivos o causales para solicitar la anulación de un laudo se encuentran enumerados taxativamente en el art. 31 de la Ley de Mediación y Arbitraje, causales de anulación que tienen dos características fundamentales: a) son taxativas $\mathrm{y} b$ ) se refieren a irregularidades adjetivas o errores in procedendo, mas no a irregularidades sustantivas o errores in judicando [...] respecto al laudo arbitral y la acción de nulidad, las causales son tasadas por el legislador $[\ldots]^{60}$.

De lo transcrito se desprende entonces que el Presidente determinó: (i) que las únicas causales de nulidad de un laudo son las del artículo 31 de la LAM y no las del COGEP ni ninguna otra norma; (ii) que estas causales son taxativas; y (iii) que está vedado cualquier juzgador que resuelva una acción de nulidad de laudo, de revisar irregularidades sustantivas, debiendo limitarse única y exclusivamente a irregularidades adjetivos o errores in procedendo.

También realizó una precisión adicional respecto del argumento de la aplicabilidad de las causales de nulidad

58. Corte Suprema de Justicia, Latin American Telecom Inc. c. Pacifictel, Proceso No. 242-1007, 11/07/2007, RO Sup. 542 06/03/2009.

59. Código Orgánico General de Procesos, N. 7, Art. 112.

60. Corte Provincial de Justicia del Azuay, N. 57. 
de sentencia reguladas en el COGEP en desmedro de la LAM, señalando que ambas normas coexisten en nuestro ordenamiento jurídico y no se contraponen al existir una especificidad en su ámbito de aplicación:

En cuanto a lo que sostiene el demandado respecto al artículo 112 del COGEP, que prevalece y se impone estableciendo como causales de nulidad exclusivamente las señaladas en esa norma, en aplicación de los principios de igualdad y seguridad jurídica que ordena la Constitución, el suscrito Juez considera que este artículo señala en aplicación del principio de especificidad y legalidad, las causas en las que una sentencia ejecutoriada que pone fin al proceso es nula, pretensión respecto a la cual tiene competencia para tramitar y resolver, el juez de primera instancia; la Ley de Arbitraje y Mediación establece por su parte las causales específicas respecto a la nulidad del Laudo Arbitral, por lo que no encuentro que la coexistencia de estas dos normas en nuestro ordenamiento jurídico, que si bien tratan respecto a causas de nulidad -de la sentencia y del Laudo Arbitral-afecte la unidad y coherencia de nuestro ordenamiento jurídico, corrobora lo expuesto, que la Corte Nacional de Justicia, posterior a la vigencia plena del COGEP dictó la Resolución $\mathrm{N}^{\circ}$ 082017 que trata de las Reglas para el Trámite de la Acción de Nulidad de Laudo Arbitral, lo que ratifica la coexistencia de las dos normativas, porque no se contraponen y su propósito es específico y especial en cada caso ${ }^{61}$.

\section{Sobre la causal de nulidad prevista en el artículo 31(d) de la LAM}

Ya en el análisis concreto de la causal, se desechó la primera hipótesis (referente a que el laudo se refirió a cuestiones no sometidas al arbitraje, al no referirse en su parte expositiva a la reconvención) argumentando que, en el laudo, si bien el árbitro no se refiere a las pretensiones de la reconvención, sí se refiere a las excepciones que ahí fueron propuestas, y que, conforme el artículo 95 del COGEP -referente al contenido de la sentencia escrita- es permisible que los hechos que constan

61. Ibídem. 
en la sentencia puedan constituir una enunciación breve. Es decir, no existe una obligación del árbitro, al motivar su laudo, de narrar todos y cada uno de los antecedentes procesales sino únicamente los relevantes para la decisión.

Adicionalmente, la sentencia hace hincapié en que cualquier alegación que pretenda una nulidad, debe fundamentarse la influencia del hecho o acto impugnado en las garantías del debido proceso (principio de trascendencia) lo cual no se ha verificado en el caso concreto.

Respecto de la segunda hipótesis planteada (extralimitación por disponer el pago de intereses que no fueron solicitados), el Presidente determinó que, revisados el texto de la reconvención, así como la contestación a la reconvención, no cabe duda de que este rubro no fue solicitado por la parte reconviniente. Sin embargo, a efectos de aplicar la sanción de nulidad prevista en el artículo 31 de la LAM, consideró que debe interpretarse esta causal de nulidad "en relación con otras disposiciones [...] que guardan plena armonía y concordancia" ${ }^{62}$.

El Presidente manifestó que, con fundamento en el artículo 3 de la LAM el árbitro debía, por obligación del principio iura novit curia aplicar el las normas de derecho pertinentes así no hayan sido invocadas por las partes ${ }^{63}$.

Para el caso concreto, y en virtud del artículo 37 ibídem, se determinó que las normas a plicables eran entre otras, el artículo 1575 del Código Civil -intereses por mora- así como en los artículos 140 del COFJ y 91 del COGEP que hacen referencia a las omisiones sobre puntos de derecho, disponiendo ambas normas en forma casi idéntica que, si bien los juzgadores deben aplicar el derecho que corresponda al proceso, así no

62. Ibídem.

63. Ibídem. 
haya sido invocado o haya sido invocado erróneamente por las partes, existe una limitante que consiste en que el juzgador no podrá otorgar o declarar mayores o diferentes derechos a los pretendidos por las partes.

Sobre la base de lo expuesto, el Presidente determinó que pese a existir intereses legales, no existe norma alguna en el Código Civil que faculte a un juzgador a ordenar de oficio el pago de intereses que no han sido reclamados, manifestando:

Sobre el contenido de los artículos del Código Civil que invoca la parte accionada, para sostener que el Arbitraje siendo en derecho se los tenía que aplicar, y que lo que ha concedido, es el costo del dinero, por lo que se ha reconocido su derecho, de su lectura no aparece que ellos faculten ordenar el pago de intereses de oficio, artículos como el 1575 se refieren a intereses convencionales, disposiciones especiales que autoricen el cobro de intereses, situaciones en las que el acreedor sólo cobra intereses, nada de aquello es aplicable a este caso, que conforme a la normativa procesal citada, más bien existe prohibición expresa de ordenar algo que no se solicitó en la pretensión (énfasis añadido) ${ }^{64}$.

Por último, el Presidente recalcó que la nulidad de un laudo arbitral debe ser declarada "en forma excepcional" y resolvió aceptar la acción de nulidad del laudo, por cuanto se ordenó el pago de intereses que no fueron reclamados.

Si bien esta sentencia no constituye jurisprudencia vinculante, resultará de consulta obligatoria como un precedente para futuras acciones de nulidad en el Azuay.

\section{Consideraciones finales}

El actuar de los diversos jueces y tribunales de la justicia ordinaria en los casos analizados nos ha dejado las siguientes reflexiones:

64. Ibídem. 
i. Existen jueces ordinarios, como hemos visto en el caso de la acción de protección y la acción de nulidad, que respetan la alternabilidad del arbitraje, determinando que, por regla general, las decisiones emitidas en el marco de un proceso arbitral no pueden ser revisadas por la justicia ordinaria (al menos hasta el dictado del laudo), y que inclusive en el marco de una acción de nulidad (y consideramos que en una acción extraordinaria de protección también), no puede conocer ningún juez o tribunal ordinario sobre el fondo de la controversia ni revisar la decisión que se haya dado en el proceso arbitral.

ii. Por otro lado, resulta preocupante el criterio vertido por la sala de admisión de la Corte Constitucional que ha admitido a trámite una acción extraordinaria de protección en contra de una decisión (auto) mediante la cual el tribunal resuelve sobre su propia competencia para conocer una causa puesta a su conocimiento.

Independientemente de lo que se resuelva sobre el fondo de la controversia, constituye un precedente sumamente grave que la sala de admisión del máximo órgano de interpretación y justicia constitu cional, tácitamente pues no existe fundamentación alguna al respecto- haya determinado que las decisiones de competencia de los tribunales arbitrales están sujetas a un control constitucional mediante la acción extraordinaria de protección.

Este hecho afecta uno de los principios elementales del arbitraje, el kompetenz-kompetenz, pues no es casualidad que la LAM (ley especial) no haya previsto un mecanismo de impugnación de estas decisiones, ni siquiera en el marco de una acción de nulidad como sí ocurre en otros países.

Se afecta también gravemente al principio de alternabilidad del arbitraje, puesto que, si el arbitraje está pensado para ser 
autónomo, distinto e independiente de la justicia ordinaria, resultaría un contrasentido que las decisiones tomadas en el marco de proceso arbitrales puedan ser impugnadas ante la justicia ordinaria (imaginemos no solo el caso de decisiones de competencia sino decisiones respecto de los medios probatorios que se practicarán en una controversia, decisiones sobre recusación de árbitros, decisiones respecto de la prueba para mejor resolver, etc.).

Sobra decir que esto traería además diversas consideraciones de índole económico (costos de las partes y riesgos del proceso), pues al no suspenderse el acto impugnado mientras se discute en sede constitucional, existiría la posibilidad de que laudos firmes y posiblemente ejecutados puedan ser anulados ex post al determinarse que el tribunal tomó una decisión vulneratoria de derechos en un momento específico de la tramitación de un proceso.

No deja de ser interesante, sin embargo, el debate existente respecto de la tensión entre la alternabilidad del arbitraje y la imposibilidad de renunciar a (los mecanismos de tutela de) derechos constitucionales.

iii. La decisión tomada en la acción de protección, respetó la alternabilidad del arbitraje determinando que, mediante esta garantía, ningún juez constitucional puede analizar la legalidad o legitimidad de una resolución tomada en el marco de un proceso arbitral.

Esta decisión resulta extremadamente lógica y coherente, reforzando la alternabilidad y autonomía del arbitraje, aunque en cierto sentido paradójica, puesto que para defender la alternabilidad del arbitraje y su distinción o separación de la justicia ordinaria, se tuvo que recurrir a las semejanzas entre las funciones y facultades de los 
árbitros en relación con los jueces, para poder justificar la causal de improcedencia constante en la LOGJCC.

iv. Si bien la sentencia de la acción de protección determinó la improcedencia de la garantía jurisdiccional en contra de la decisión de competencia de un tribunal arbitral, se declaró con lugar una medida cautelar constitucional que dispuso suspender la tramitación de un proceso arbitral.

Este hecho, constituye otra afectación a la alternabilidad del arbitraje puesto que, abre camino a que partes que no litiguen de buena fe, o incluso partes que estén poco familiarizadas con la naturaleza de un proceso arbitral, puedan pretender retardar las causas en que se vean inmersos vía la interposición de esta garantía constitucional, inclusive antes del dictado del laudo.

Imaginemos las consecuencias que podría traer al sistema arbitral, el que las partes puedan interponer medidas cautelares constitucionales que suspendan la tramitación de la causa, alegando que se pretende "evitar o cesar la amenaza o violación" de sus derechos constitucionales, violación que podría materializarse en los múltiples tipos de decisiones que puede tomar un tribunal arbitral, tal como se señaló en el punto ii) de este acápite.

v. En el juicio de acción extraordinaria de protección, resultaría interesante un pronunciamiento de la Corte Constitucional - más allá de lo discutible que puedan ser sus facultades respecto de este punto específico - en el que se determine (i) si efectivamente una decisión de competencia de un tribunal arbitral es susceptible de esta garantía constitucional y, en caso de ser afirmativa la respuesta, (ii) cuál es el estándar al que deben sujetarse los árbitros o tribunales arbitrales al momento de decidir sobre su propia competencia, precisamente al ser un tema 
no del todo reglado en nuestro ordenamiento jurídico y cuya aplicación queda en la gran mayoría de casos a voluntad del tribunal (independientemente de las buenas prácticas que puedan existir y/o de lo que dispongan los reglamentos de los distintos centros).

Si bien el solo hecho de que exista un pronunciamiento semejante afectaría indiscutiblemente el principio kompetenzkompetenz, pues se lo estaría reglando en cierta forma, no es menos cierto que serviría como un punto de discusión el saber, por ejemplo, si a criterio de nuestro máximo órgano de justicia constitucional, constituye una violación del debido proceso el que un tribunal analice y valore las pruebas aparejadas al proceso para tomar su decisión de competencia, o si los árbitros deben ceñirse al texto frío del convenio arbitral, estándoles vedado revisar pruebas que en muchos casos no han podido ser sujetas a contradicción o cualquier objeción de admisibilidad que podría tener una de las partes. 